A.V. MANDRIK ${ }^{1}$

A.E. TROSHIN ${ }^{1}$

V.E. KISEL ${ }^{1}$

A.S. YASUKEVICH ${ }^{1, \infty}$

G.N. KLAVSUT ${ }^{1}$

N.V. KULESHOV ${ }^{1}$

A.A. PAVLYUK ${ }^{2}$

\section{CW and Q-switched diode-pumped laser operation of $\mathrm{Yb}^{3+}: \mathrm{NaLa}\left(\mathrm{MoO}_{4}\right)_{2}$}

\author{
${ }^{1}$ International Laser Center, Bldg. 17, \#65 F. Skaryna Ave., 220013 Minsk, Belarus \\ ${ }^{2}$ Institute of Inorganic Chemistry, Siberian Branch of Russian Academy of Novosibirsk, Novosibirsk Russia
}

\section{Received: 14 April 2005/Revised version: 7 July 2005} Published online: 8 October 2005 • (C) Springer-Verlag 2005

ABSTRACT Continuous wave $(\mathrm{CW})$ and Q-switched diodepumped laser operation of $\mathrm{Yb}^{3+}: \mathrm{NaLa}\left(\mathrm{MoO}_{4}\right)_{2}$ single crystal was to our knowledge, demonstrated for the first time. A CW output power of $220 \mathrm{~mW}$ and slope efficiency of $46 \%$ were obtained. Q-switched laser operation was achieved with a pulse duration of $60 \mathrm{~ns}$ average output power of $70 \mathrm{~mW}$ and slope efficiency of $22 \%$.

PACS 42.55.Xi; 42.60.Pk; 42.60.Gd.

1

\section{Introduction}

$\mathrm{New} \mathrm{Yb}^{3+}$-doped laser crystals are of high interest due to favorable spectroscopic parameters of $\mathrm{Yb}$ ion for built up efficient high power directly diode-pumped lasers, and for generation of femtosecond pulses. Laser related spectroscopy and oscillation of a number of materials doped with $\mathrm{Yb}^{3+}$ ions were intensively investigated (see e.g. [1-3]). Special attention is paid to host matrices with mixed cations which cause a disordered environment of ytterbium ions. This results in more broad and smooth gain bands in comparison with ordered crystals. The spectroscopic data for $\mathrm{Yb}$ disordered crystals with the general formula $\mathrm{Yb}: \mathrm{NaR}\left(\mathrm{MeO}_{4}\right)_{2}(\mathrm{R}=\mathrm{La}$, $\mathrm{Gd} ; \mathrm{Me}=\mathrm{W}, \mathrm{Mo})[4,5]$, indicate that ultrashort pulses with duration of less than $50 \mathrm{fs}$ could be generated. So, detailed studies of spectroscopic properties and laser characteristics of these materials will give an opportunity to estimate their real potential for ultrafast lasers.

Here we present the results of spectroscopic investigations of $\mathrm{Yb}^{3+}: \mathrm{NaLa}\left(\mathrm{MoO}_{4}\right)_{2}(\mathrm{Yb}: \mathrm{NLM})$ crystal grown by the Czochralski technique, along with diode-pumped laser experiments in CW and Q-switched modes of operation. Preliminary spectroscopic parameters of this material were reported in [6]. It is also important to note that NLM is an efficient Raman active medium [7,8].

\section{Spectroscopic properties}

Yb-doped Yb:NLM single crystal was grown by Czochralski technique from the melt. As raw materials the

Fax: +375-172-326-286, E-mail: anatol@ilc.by crystals of $\mathrm{NaLa}\left(\mathrm{MoO}_{4}\right)_{2}(95 \mathrm{~mol} \%)$ and polycrystalline ceramics of $(5 \mathrm{~mol} \%) \mathrm{NaYb}\left(\mathrm{MoO}_{4}\right)_{2}$ were used. The crystal was pulled along the [001] direction and a sample of about $25 \mathrm{~mm}$ in diameter and $40 \mathrm{~mm}$ in length was grown. NLM crystal has a tetragonal sheelite-like structure with space group $I 4_{1} a\left(C_{4 h}^{6}\right)[9,10] . \mathrm{Na}^{+}$and $\mathrm{La}^{3+}$ ions are distributed randomly between eightfold coordinated $4 a$ sites. The content of ytterbium ions in the crystal was determined to be equal to 1.57 at. \% by means of atomic-emission analysis. It means that the segregation coefficient for $\mathrm{Yb}^{3+}$ ions is about 0.3 . Absorption cross-sections $\sigma_{\text {abs }}^{\alpha}(\lambda)$ for different light polarizations $(\alpha=\pi, \sigma)$ were determined from absorption spectra recorded with a spectral resolution of $0.6 \mathrm{~nm}$ (Fig. 1). Peak absorption cross sections for $\pi$ and $\sigma$ polarization at $977 \mathrm{~nm}$ are $2.5 \times 10^{-20} \mathrm{~cm}^{2}$ and $1.5 \times 10^{-20} \mathrm{~cm}^{2}$, respectively. For $\sigma$ polarization there is another peak of $1.3 \times 10^{-20} \mathrm{~cm}^{2}$ at $934 \mathrm{~nm}$.

Emission lifetime was measured to be $285 \pm 10 \mu$ s from luminescence decay curves of fine crystalline powder of $\mathrm{Yb}:$ NLM immersed in ethylene-glycol. Such a technique allows avoidance of radiation trapping which is very important for Yb-doped materials as quasi three-level active media [11]. Our results correlate with corresponding data reported in [6].

Detailed energy level structures of two manifolds ${ }^{2} F_{7 / 2}$ (lower) and ${ }^{2} F_{5 / 2}$ (upper) of $\mathrm{Yb}^{3+}$ ion in NLM has not estimated so far. The spectra of stimulated emission cross section

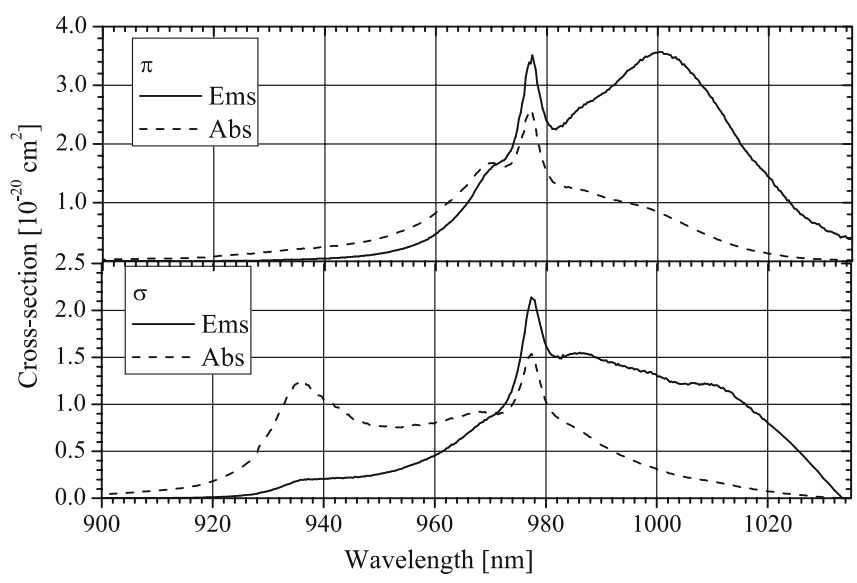

FIGURE 1 Polarized absorption and stimulated emission cross-section spectra of $\mathrm{Yb}: \mathrm{NLM}$ at room temperature 
$\sigma_{\mathrm{em}}^{\alpha}(\lambda)$ for light polarizations $(\alpha=\pi, \sigma)$ were determined by means of the modified (integral) reciprocity method [12]:

$$
\begin{aligned}
& \sigma_{\mathrm{em}}^{\alpha}(\lambda)= \\
& 8 \pi n^{2} \tau_{\mathrm{rad}} c\left[\sum_{\beta} \int \lambda^{-4} \sigma_{\mathrm{abs}}^{\beta}(\lambda) \exp (-h c /(k T \lambda)) \mathrm{d} \lambda\right]
\end{aligned} \sigma_{\mathrm{abs}}^{\alpha}(\lambda),
$$

where $\lambda$ is the light wavelength, the index $\beta$ characterizes a light polarization state, $\tau_{\text {rad }}$ is a radiative lifetime, $T$ is a host crystal temperature, $h$ and $k$ are the Plank's and Boltzman's constants, respectively, $c$ is the light speed in a vacuum, and $n=2$ is the refraction index of the host crystal. Emission spectra demonstrate broad band between $980 \mathrm{~nm}$ and $1040 \mathrm{~nm}$ with maximum at $1000 \mathrm{~nm}$ and $1010 \mathrm{~nm}$ for $\pi$ - and $\sigma$-polarizations, respectively.

\section{$3 \quad$ Laser experiments}

Continuous wave laser experiments were carried out with a nearly hemispherical laser cavity. It was comprised of a $50 \mathrm{~mm}$ radius-of-curvature output coupler (OC) and a plane high reflector in the spectral range of $1020-1100 \mathrm{~nm}$. Yb:NLM crystal was cut so that its optical axis was perpendicular to the cavity axis for possible laser operation in both $\pi$ and $\sigma$ polarizations. The laser element with a thickness of $2.5 \mathrm{~mm}$ was antireflection coated at the pump and laser wavelengths and mounted onto an aluminium heatsink kept at about $10^{\circ} \mathrm{C}$. We used a $\mathrm{CW}$ fiber-coupled $(\emptyset=100 \mu \mathrm{m}$, N.A. $=0.22$ ) laser diode (LD) with an output power of $8 \mathrm{~W}$ at $980 \mathrm{~nm}$ as a pump source. The pump beam was focused into a circular spot with a diameter of $110 \mu \mathrm{m}$ and a confocal length of about $2.5 \mathrm{~mm}$ inside the crystal. The diameter of the $\mathrm{TEM}_{00}$ transversal mode of the cavity in the active element was close to the pump beam waist $(110 \mu \mathrm{m})$. Input-output diagrams for a $\mathrm{Yb}$ :NLM laser in CW mode of operation with OC transmittance (Toc) of $1 \%$ and 3.5\%, are given in Fig. 2 .

For both output couplers we obtained approximately the same maximum output powers of about $220 \mathrm{~mW}$ at absorbed pump powers of $785 \mathrm{~mW}$ and $775 \mathrm{~mW}$, respectively. Slope efficiency reached $46 \%$ with Toc $=3.5 \%$. The laser threshold was $147 \mathrm{~mW}$ of absorbed pump power for $1 \% \mathrm{OC}$ and $225 \mathrm{~mW}$ for $3.5 \%$ OC. Due to the quasi three level scheme of laser operation of $\mathrm{Yb}: \mathrm{NLM}$ the output wavelength was shifted from $1017 \mathrm{~nm}$ for $3.5 \%$ OC to $1023 \mathrm{~nm}$ for $1 \%$ OC. For both cases the output laser emission was $\pi$-polarized due to a higher stimulated emission cross section for this polarization $\left(\sigma_{\mathrm{em}}^{\pi}=1.7 \times 10^{-20} \mathrm{~cm}^{2}\right.$ at $\left.1017 \mathrm{~nm}\right)$. Very recently in [4], laser performance of $\mathrm{Yb}(2.2$ at. \%):NLM under Ti:sapphire laser excitation at $976.6 \mathrm{~nm}$ was reported. A laser threshold absorbed pump power of $150 \mathrm{~mW}$ (Toc $=1.1 \%$ ), slope effi-

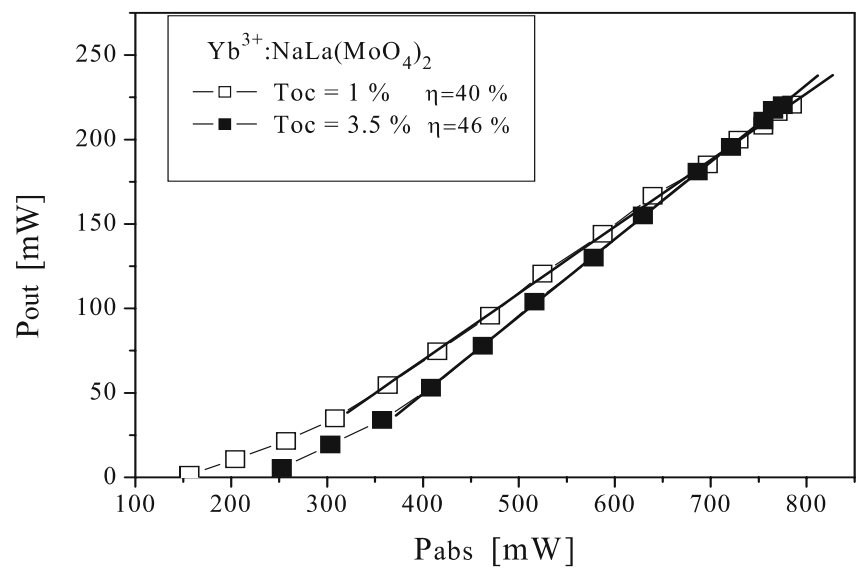

FIGURE 2 Output power versus absorbed power of cw Yb:NLM laser

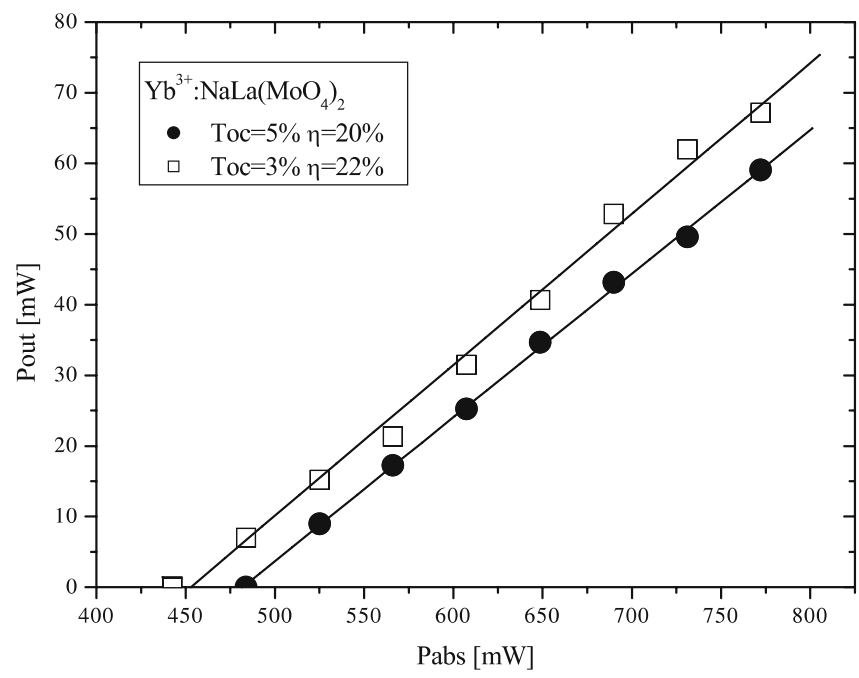

FIGURE 3 Output power versus absorbed power of Q-switched Yb:NLM laser

ciency of $30 \%($ Toc $=5.4 \%)$ and tunability from 1015 to 1053 was demonstrated.

For Q-switched laser experiments the same cavity configuration was used. The antireflection coated $\mathrm{Cr}^{4+}$ :YAG crystal with a thickness of $120 \mu \mathrm{m}$ was used as a passive shutter. The shutter has an initial transmittance of about $97 \%$ at $1020 \mathrm{~nm}$ and was mounted onto the opposite side of the heat sink $4 \mathrm{~mm}$ apart from the active element. In Q-switched mode average output power was $70 \mathrm{~mW}$ and $63 \mathrm{~mW}$ with slope efficiencies of $22 \%$ and $20 \%$ for $3.5 \%$ and $5 \%$ OCs, respectively. The Q-switched laser operated at wavelength $\lambda_{\mathrm{p}}=1010 \mathrm{~nm}$ for both OCs. Input-output diagrams for the Qswitched laser are shown in Fig. 3. The shortest light pulse duration $\tau_{\mathrm{p}}$ of $60 \mathrm{~ns}$ was obtained with a Toc of $3.5 \%$ with maximal repetition rate $f$ of $25 \mathrm{kHz}$. The summary of the results of Q-switched laser experiments is presented in Table 1. A conversion efficiency is a ratio between the average out-
TABLE 1 The parameters of Q-switched diode-pumped Yb:NLM laser with Cr:YAG saturable absorber

\begin{tabular}{lccccccc}
\hline $\begin{array}{l}\text { Toc, } \\
\%\end{array}$ & $\begin{array}{c}\text { Average output } \\
\text { power, } \mathrm{mW}\end{array}$ & $\begin{array}{c}\text { Pulse energy, } \\
\mu \mathrm{J}\end{array}$ & $\begin{array}{c}\text { Slope efficiency, Conversion } \\
\%\end{array}$ & $\begin{array}{c}\tau_{\mathrm{p}}, \\
\text { efficiency, } \%\end{array}$ & $\begin{array}{c}f, \\
\mathrm{kHz}\end{array}$ & $\begin{array}{c}\lambda_{\mathrm{p}}, \\
\mathrm{nm}\end{array}$ \\
\hline 3.5 & 70 & 2.8 & 22 & 40 & 60 & 25 & 1010 \\
5 & 63 & 2.84 & 20 & 48 & 72 & 22.2 & 1010 \\
\hline
\end{tabular}


put power in Q-switched mode and the output power in CW mode for the same OC. Though NLM crystals are efficient Raman media we did not observe frequency conversion in our experiments.

\section{4}

\section{Conclusion}

High quality $\mathrm{Yb}^{3+}: \mathrm{NaLa}\left(\mathrm{MoO}_{4}\right)_{2}$ single crystal doped with 1.57 at. $\%$ of $\mathrm{Yb}^{3+}$ ions was grown by the Czochralski technique. Absorption and stimulated emission cross-section spectra for $\pi$ and $\sigma$ polarizations were determined. The gain band of smooth shape for $\pi$ polarization is extended approximately over $70 \mathrm{~nm}$ which is very attractive for generation of light pulses of femtosecond duration. Radiative lifetime for $\mathrm{Yb}^{3+}$ ions was measured to be $285 \mu \mathrm{s}$. The CW and Q-switched laser operations of $\mathrm{Yb}^{3+}$ :NLM crystal under longitudinal laser diode pumping at $980 \mathrm{~nm}$ was demonstrated. A CW slope efficiency of $46 \%$ with maximum output power of $220 \mathrm{~mW}$ was achieved. In the Q-switched regime an average output power of $70 \mathrm{~mW}$ with a slope efficiency of $22 \%$, repetition rate of $25 \mathrm{kHz}$, and pulse duration of $60 \mathrm{~ns}$ was obtained. Spectroscopic and laser properties demonstrate the high promise of the $\mathrm{Yb}^{3+}: \mathrm{NaLa}\left(\mathrm{MoO}_{4}\right)_{2}$ crystals for femtosecond pulse generation.

\section{REFERENCES}

1 L.D. DeLoach, S.A. Payne, L.L. Chase, L.K. Smith, W.L. Kway, W.F. Krupke, IEEE J. Quantum Electron. QE-29, $1179(1993)$

2 W.F. Krupke, IEEE J. Sel. Top. Quantum Electron. 6, 1287 (2000)

3 A. Brenier, J. Lumin. 92, 199 (2001)

4 J. Liu, J.M. Cano-Torres, C. Cascales, F. Esteban-Betegon, M.D. Serrano, V. Volkov, C. Zaldo, M. Rico, U. Ceribner, V. Petrov, Phys. Stat. Solidi A 202, 29 (2005)

5 M. Rico, J. Liu, U. Griebner, V. Petrov, M.D. Serrano, F. EstebanBetegon, C. Cascales, C. Zaldo, Opt. Express 22, 5362 (2004)

6 Y.K. Voron'ko, E.V. Zharikov, D.A. Lis, A.A. Sobol, K.A. Subbotin, S.N. Ushakov, V.E. Shukshin, Proc. SPIE 5478, 60 (2004)

7 T.T. Basiev, A.A. Sobol, Y.K. Voronko, P.G. Zverev, Opt. Mater. 15, 205 (2000)

8 P.G. Zverev, T.T. Basiev, A.M. Prokhorov, Opt. Mater. 11, 335 (1999)

9 M.V. Mohosoev, V.I. Krivobok, C.M. Aleikina, N.S. Zhigulina, N.C. Kisel, Inorg. Mater. 3, 1657 (1967)

10 S.B. Stevenson, C.A. Morrison, T.H. Allik, A.L. Rheingold, B.S. Haggerty, Phys. Rev. B 43, 7386 (1991)

11 D.S. Sumida, T. Fan, Opt. Lett. 19, 1343 (1994)

12 A.S. Yasukevich, V.G. Shcherbitskii, V.E. Kisel, A.V. Mandrik, N.V. Kuleshov, Appl. Spectrosc. 71, 202 (2004) 